\title{
Management of Thoracic Impalement Injury in Ghana: A Five-Year Experience at the Komfo Anokye Teaching Hospital
}

\author{
Isaac Okyere ${ }^{1,3 *}$, Samuel Gyasi Brenu1,3, Perditer Okyere ${ }^{2,3}$ \\ ${ }^{1}$ Cardiovascular and Thoracic Surgery Unit, Department of Surgery \\ ${ }^{2}$ Renal Unit, Department of Medicine \\ ${ }^{3}$ School of Medicine and Dentistry, College of Health Sciences, Kwame Nkrumah University of Science and Technology \\ and Komfo Anokye Teaching Hospital, Kumasi, Ghana \\ Email: *drokyere@yahoo.com
}

How to cite this paper: Okyere, I., Brenu, S.G. and Okyere, P. (2019) Management of Thoracic Impalement Injury in Ghana: A Five-Year Experience at the Komfo Anokye Teaching Hospital. World Journal of Cardiovascular Surgery, 9, 119-131.

https://doi.org/10.4236/wjcs.2019.99014

Received: August 10, 2019

Accepted: September 13, 2019

Published: September 16, 2019

Copyright $\odot 2019$ by author(s) and Scientific Research Publishing Inc. This work is licensed under the Creative Commons Attribution International License (CC BY 4.0).

http://creativecommons.org/licenses/by/4.0/

\begin{abstract}
Impalement injuries are rare and among the most spectacular and dramatic traumatic injuries especially of the chest. The survival of a patient with a thoracic impalement injury can be extremely rare. Herein we present and discuss our successes of the management of 7 rare cases of thoracic impalement injuries over a 5-year period from January 2014 to June 2019 at the Komfo Anokye Teaching Hospital, Kumasi in Ghana. We discuss the presentation, diagnosis, treatment and outcomes of the seven cases encountered.
\end{abstract}

\section{Keywords}

Foreign Body, Impalement Injury, Thoracic Injury, Thoracotomy, Sternotomy

\section{Introduction}

Impalement injury is an uncommon form of trauma encountered rarely in a surgeon's career. These injuries are spectacular and dramatic, and due to the multiple lesions they may associate, they represent a challenge even for an experienced surgeon. The literature presents only few survival cases, the vast majority being unfortunately fatal. However, survival of a patient with thoracic impalement injury is possible even in less resourced centers if the impaling object is not removed in the field and coupled with rapid transport of the patient to an appropriate hospital for stabilization and early emergency surgery. Applying these principles, we discuss the successful management of impalement injuries in our hospital over a 5-year period from January 2015 to June 2019. 


\section{Case Series}

\subsection{Case 1}

Patient was a 22-year-old young man who presented with a left-sided sharp non-radiating pleuritic chest pain after allegedly been stabbed in his left chest with a knife 10 hours prior to presentation by one of his friends while attempting to intervene in a fight amongst them. He immediately started bleeding profusely from the site and was rushed to a peripheral hospital with the knife still in situ in the left infraclavicular region. Intravenous fluids were administered and the knife stabilized by bandaging infusion bags around it and then referred to our centre for further management. On arrival, the patient was hemodynamically stable with blood pressure of 124/65 $\mathrm{mmHg}$, pulse rate of 94 beats/minute that was regular and of good volume. Respiratory rate was 24 cycles/minute and saturating at $95 \%$ on room air. Air entry was reduced over the left hemithorax anteriorly with vesicular breath sounds and no added sounds. A knife was seen penetrating the chest through the infraclavicular region along the midclavicular line at an angle of approximately $30^{\circ}$. It had been secured with IV infusions bandaged around it. Extremities were warm with good capillary refill time and all other organ systems were clinically normal.

Chest $\mathrm{x}$-ray taken showed opacification of the left hemithorax with atelectasis and the knife penetrating the chest from the apex of the chest as shown in Figure 1 and Figure 2. Laboratory investigation showed an $\mathrm{Hb}$ of $12 \mathrm{~g} / \mathrm{dl}$, platelets of 208 and a WBC of 10.37. The chemistry showed normal ranges for urea, creatinine and electrolytes. He was given antitetanus prophylaxis, antibiotics, started on intravenous Normal Saline Infusion and blood was quickly taken to group-match against 4 units of blood. He was then wheeled to the operating theatre after 2 hours of stabilization.
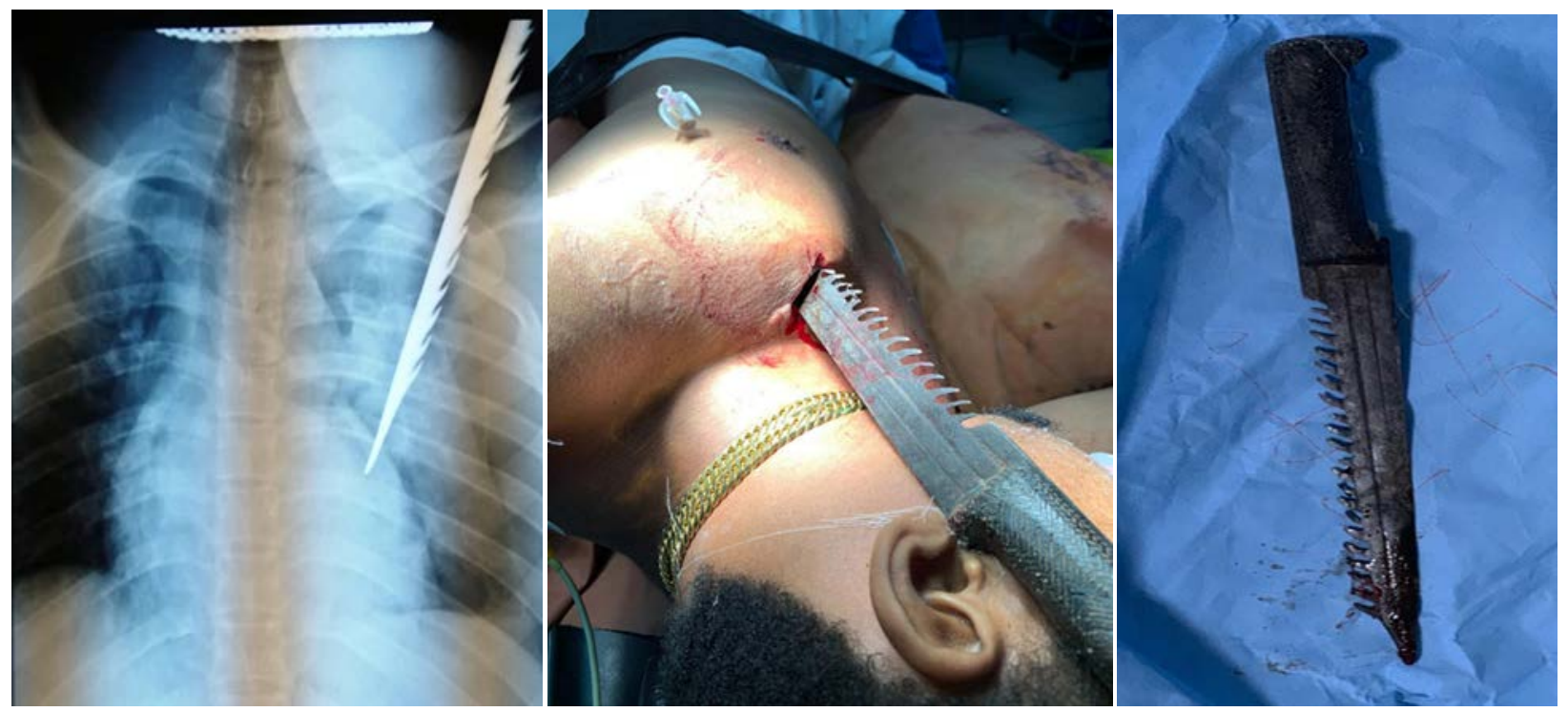

Figure 1. Chest $\mathrm{x}$-ray with impaled knife in situ with left haemothorax and atelectasis, serrated knife entering the chest through the infraclavicular region and post-removal impaled serrated knife. 


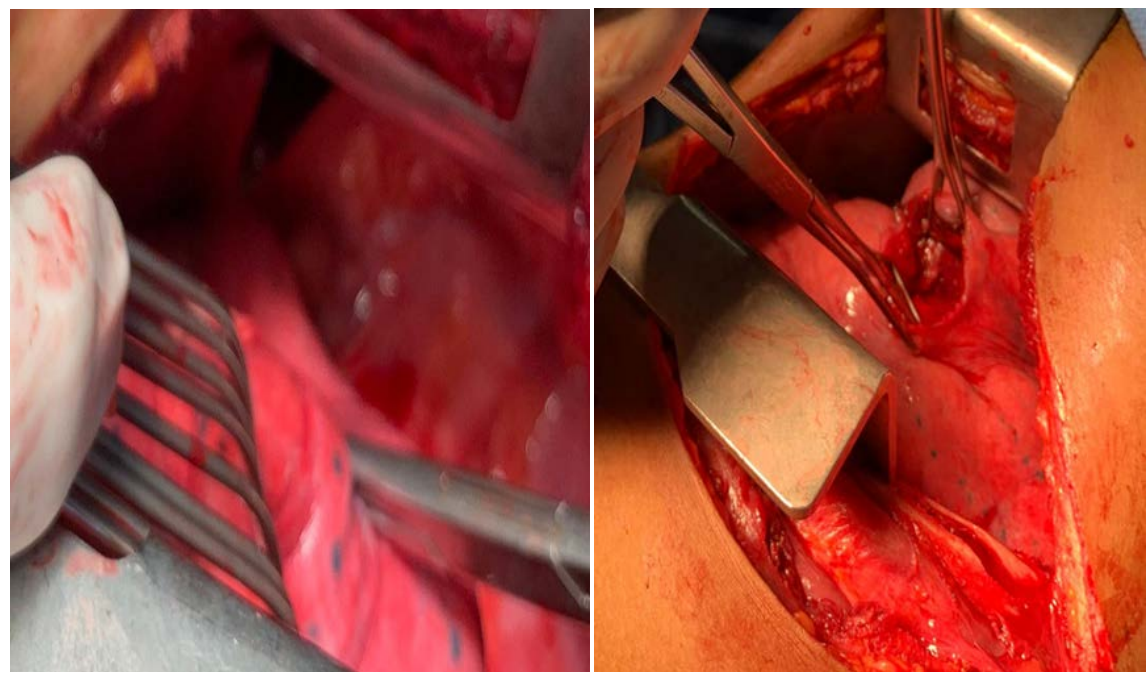

Figure 2. The tip of the knife seen intraoperatively and the ends of the lacerated left upper lobe lung.

In theatre, under aseptic conditions and general conventional anaesthesia, the chest was entered via a standard left posterolateral thoracotomy entering the $4^{\text {th }}$ intercostal space. Findings included a haemothorax of $500 \mathrm{mls}$ and a near complete transverse laceration of the apical lobe of the left lung. The tip of the serrated knife was about $2 \mathrm{~cm}$ away from the anterior pericardium, however all other mediastinal organs were intact. The knife was carefully removed and lacerated lung repaired with vicryl 4/0 after evacuating the haemothorax and cleaning the ends of the lacerated lung with povidine-iodine. The chest was toileted with warm normal saline after haemostasis, mopped clean and closed up in layers after inserting a size $32 \mathrm{~F}$ chest tube. The knife wound site was cleaned with povidine iodine and closed with Nylon 2/0. He had an uneventful postoperative period, chest tube was removed on the $3^{\text {rd }}$ postoperative day and he was discharged home on postoperative day 9 for follow-up on outpatient basis. He has been well without any sequelae 5 months after the surgery.

\subsection{Case 2}

A 34-year old female presented with a crochet pin in the chest after accidentally stabbing herself while forcefully snatching it from her child. The pin went through the xiphisternum into the chest entering the right ventricle. She was rushed to a peripheral hospital from where she was referred to the accident and emergency centre of our hospital on account of an ultrasound done which showed a pericardial collection. Associated symptoms included retrosternal non-pleuritic chest pain and palpitations but no cough, haemoptysis or dyspnea.

On arrival, she was hemodynamically stable with a $\mathrm{BP}$ of $114 / 79 \mathrm{mmHg}$, pulse rate of $113 \mathrm{bpm}$, regular and of good volume, respiratory rate of $20 \mathrm{cycles} / \mathrm{minute}$, saturating at $100 \%$ on room air. The significant finding on examination was the metallic pin penetrating the chest through the xiphisternum oscillating with cardiac activity as shown in Figure 3 and Figure 4. The air entry was adequate bi 

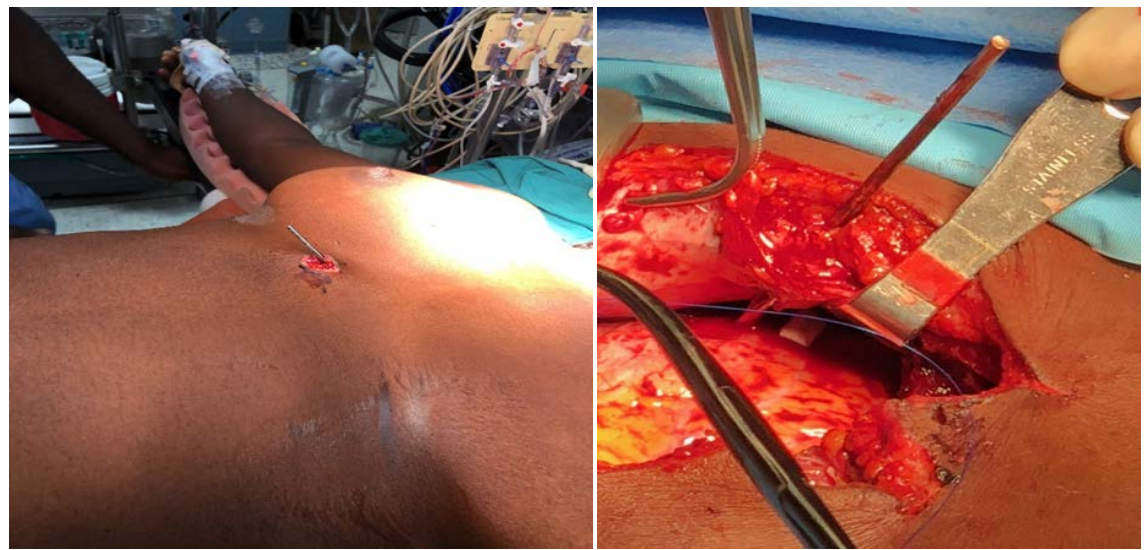

Figure 3. Showing the pin in-situ on presentation and intraoperatively showing the crochet pin in the right ventricle.
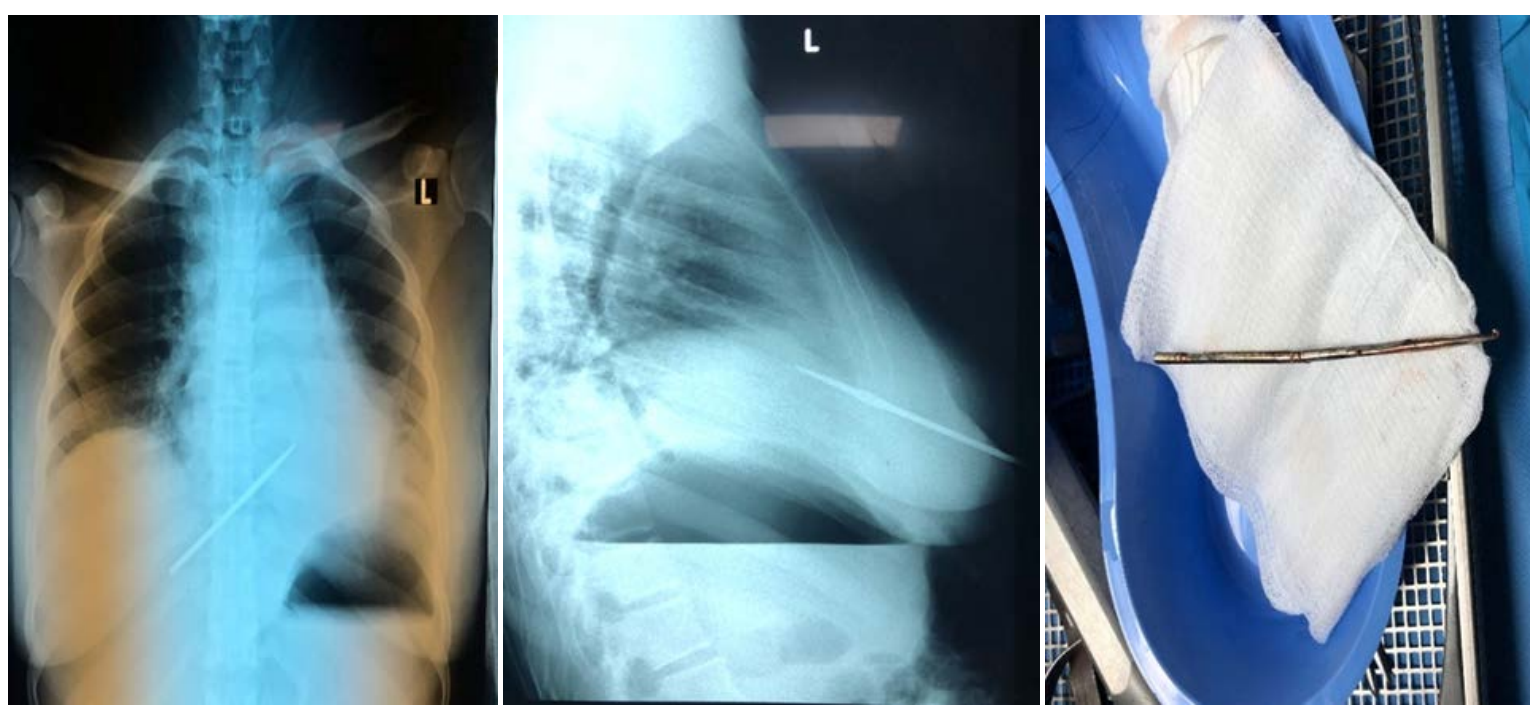

Figure 4. Chest $\mathrm{x}$-ray showing the pin entering the right ventricle and post removal.

laterally with vesicular breath sounds. Heart sounds were present but distant. All other systems were unremarkable. Urgent Echocardiography showed minimal haemopericardium with the pin in the right ventricle. Patient was prepared for exploratory sternotomy and removal of pin after obtaining informed consent. Under aseptic conditions and general anaesthesia with endotracheal intubation, the chest was entered via a median sternotomy and the intraoperative findings included moderate haemopericardium of about $300 \mathrm{ml}$, right haemothorax of approximately $500 \mathrm{ml}$ and a right ventricular perforation of $0.3 \mathrm{~cm}$ diameter with the crochet pin in situ.

The pin was carefully removed with pledgeted Teflon repair of the ventricular perforation; haemostasis was then secured. One size $20 \mathrm{Fr}$ chest tube was placed and sternal closure done with a size $6 \mathrm{Fr}$ sternal wire and skin closed in a subcuticular fashion.

Post-operatively, patient made an uneventful recovery and was subsequently discharged home on postoperative day 7 after removing the chest tube on post- 
operative day 2 for follow-up on outpatient basis. She has been well one year after surgery carrying out her normal duties.

\subsection{Case 3}

A 29-year old male presented to the accident and emergency centre of our hospital with a knife stab wound to the chest after he was allegedly attacked by armed robbers on his way home at night. He was stabbed in the left lateral chest below the nipple with all 3 pieces of a jack knife which had since gotten impaled. He started experiencing sharp left-sided chest pain with no associated cough, dyspnoea or haemoptysis. He was rushed to a peripheral hospital from where he was referred to our centre for further management after stabilizing the knife with sterile gauze.

On arrival, the patient was haemodynamically stable with BP $124 / 82 \mathrm{mmHg}$, pulse rate $85 \mathrm{bpm}$, regular, good volume and respiratory rate 16 cycles/minute, saturating at $99 \%$ on room air. He had a jack knife impaled to the left lateral chest through the $7^{\text {th }}$ intercostal space as shown in Figure 5. Air entry was adequate bilaterally with vesicular breath sounds. No bowel sounds were heard. Extended Focused Abdominal Scan for Trauma (EFAST) was negative for haemopericardium, haemoperitoneum and haemothorax. The abdomen was full, soft and non-tender with no organomegaly, guarding or rebound tenderness. Urgent laboratory investigation reported of an $\mathrm{Hb}$ of $10.6 \mathrm{~g} / \mathrm{dl}$ with normal renal function. Patient was then prepared for an exploratory left thoracotomy after obtaining informed consent. Under aseptic conditions and general anaesthesia with endotracheal intubation, the chest was entered through a standard left posterolateral thoracotomy entering the $7^{\text {th }}$ pleural bed. Intraoperative findings included a $2.5 \mathrm{~cm}$ diaphragmatic laceration by the knife and a pleural blood collection, haemothorax of $250 \mathrm{ml}$. The jack knife was removed under direct vision. After evacuating the haemothorax, the diaphragmatic laceration was repaired
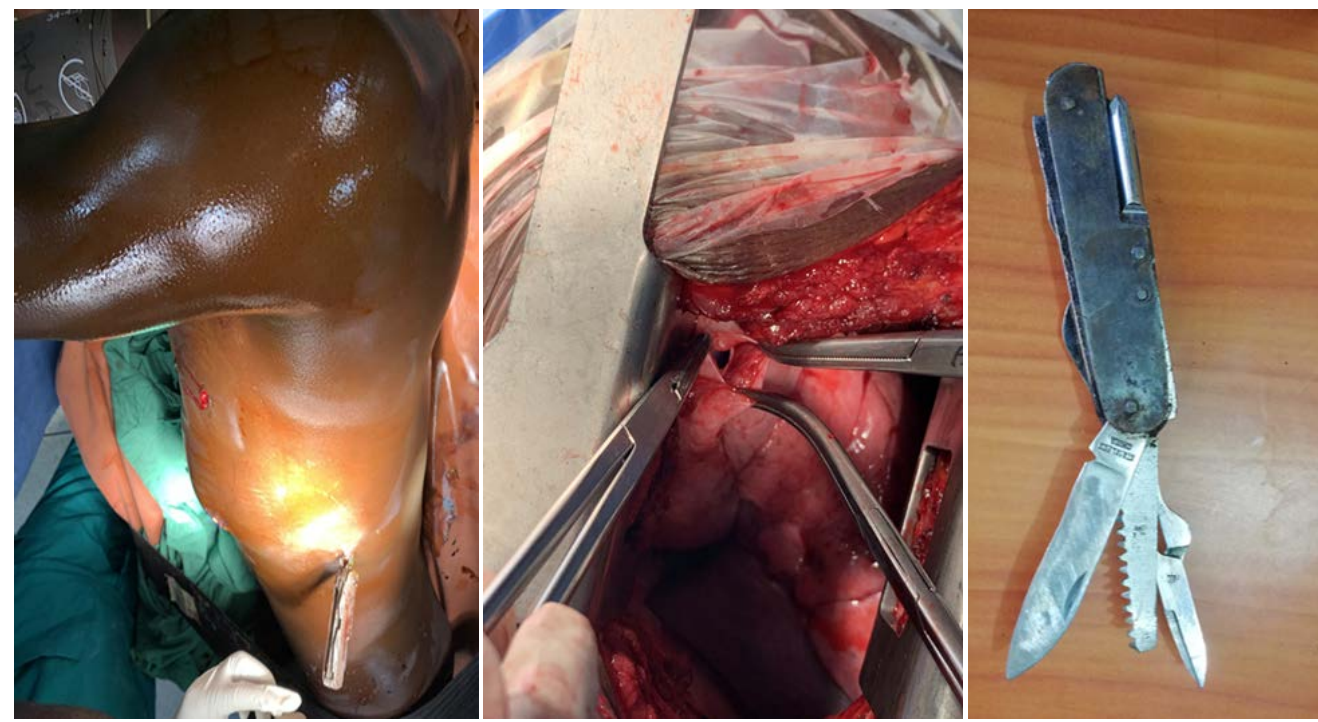

Figure 5. Showing knife in-situ, lacerated left diaphragm, and post-removal. 
with nylon 1 in a single continuous fashion. The pleural cavity was lavaged with warm normal saline and closed up in layers after inserting a $28 \mathrm{Fr}$ size chest tube. Patient recovered uneventfully postoperatively and was subsequently discharged home on postoperative day 6 , after removing the chest tube on postoperative day 2 for further follow-up on outpatient basis. He has been well for eight months now after surgery with no complications.

\subsection{Case 4}

This was a 12 year old boy who was referred to our hospital from a regional hospital on account of having been hit by a stray bullet during a festival in the northern part of the country. He had temporary been seen at the regional Hospital, given antibiotics, antitetanus prophylaxis and the wound covered with clean dry gauze before referral. Upon arrival to the accident and emergency centre of the Komfo Anokye Teaching Hospital, he looked stable but anxious looking, $\mathrm{BP}$ of 100/70 $\mathrm{mmHg}$, pulse rate of $96 \mathrm{beat} /$ minute and a respiratory cycle of 20 cycles/minute. He was saturating at $98 \%$ on room air. Air entry was adequate bilaterally.

Significant finding on removing the gauze on the wound was a rusted looking metallic ring below the left clavicle which moved with cardiac activity as shown in Figure 6. Laboratory findings were within normal ranges and therefore he was wheeled to the operating theatre with 2 units of group-matched red blood cells after informed consent. Under general anaesthesia and aseptic conditions, the wound size was extended cepahalo-caudally and the metallic ring carefully removed. There was no injury to the ascending aorta on which it was lying and fixed by the surrounding tissues. He had an uneventful postoperative period and was discharged on postoperative day 5 . He has been well two years after surgery without complications.

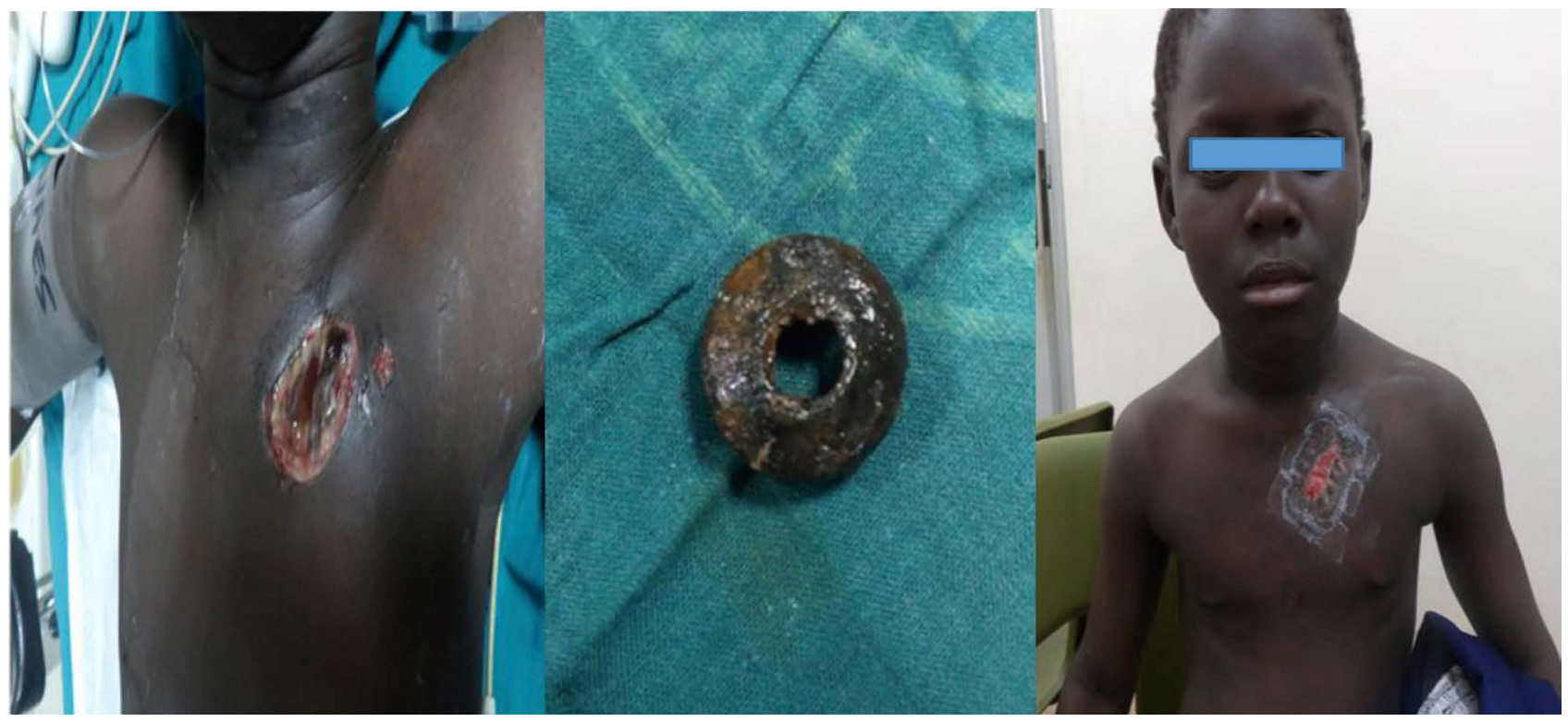

Figure 6. Bullet on aorta, removed bullet and 2 weeks postoperatively. 


\subsection{Case 5}

A 42-year-old presented to our hospital with a stick impaled to his chest after being involved in a road traffic accident. He was driving a vehicle whose brakes failed and as such drove into a nearby bush. He had a branch from a tree piercing through his chest on the left. He was briefly seen at a peripheral hospital where part of the stick was cut off and the dressing applied before being referred. At the emergency and accident centre of our hospital, he looked relatively stable with $\mathrm{BP}$ of $128 / 84 \mathrm{mmHg}$, pulse rate of 94 beats/minute, good volume and a respiratory cycle of 21 cycles/minute. He was saturating at $95 \%$ on room air with air entry moderately reduced at the left lower zone. There was a stick into the chest at the $2^{\text {nd }}$ intercostal space which moved in consonance with cardiac activity as shown in Figure 7. Hb on admission was $11.2 \mathrm{~g} / \mathrm{dl}$ and blood was group-match against four units of blood. He was prepared for exploratory thoracotomy.
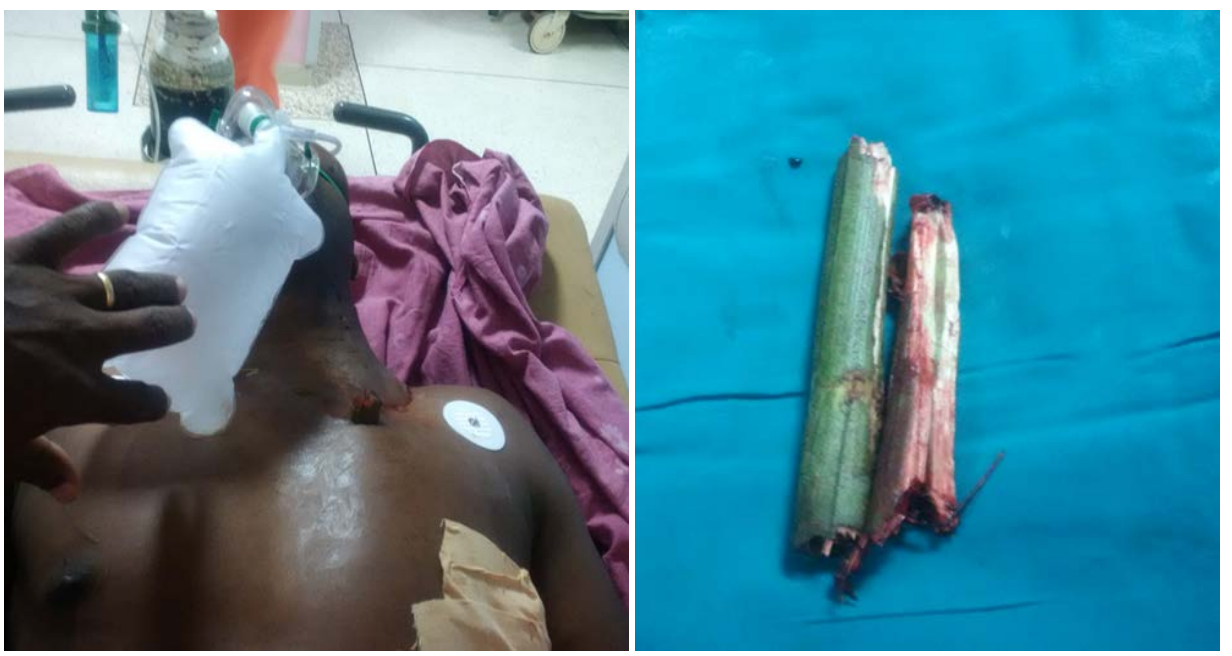

Figure 7. Showing the stick chest in-situ and removal.

In theatre with patient under general anesthesia and in right lateral decubitus position, a standard left posterolateral thoracotomy was done entering the $5^{\text {th }}$ intercostal space. There was about $350 \mathrm{ml}$ of pleural blood, which was evacuated and the stick was lying on the pericardium having lifted the left phrenic nerve of the pericardium without any damage. All the other intrathoracic organs were intact. The stick was carefully removed, pleural cavity lavaged with warm normal saline and closed up in layers after leaving a size $32 \mathrm{Fr}$ Chest tube in situ. The entry wound site was cleaned with povidine iodine and repaired with nylon 1 . He had an uneventful postoperative course and was discharged on postoperative day 10 after removing the chest on postoperative day 3 . He continued follow-up on 2 weeks, one month and three months and has been well 4 years now with no complaints.

\subsection{Case 6}

A 32-year-old was allegedly attacked by some armed robbers and presented to the accident and emergency centre of our hospital with a knife in situ right 
from the place of attack. He was relatively stable hemodynamically. His BP was 110/78 $\mathrm{mmHg}$, pulse rate of 99 beats/minute, regular and good volume. His saturation was $94 \%$ on room air, respiratory rate of 24 cycles/minute with air entry slightly reduced on the left. All other organ systems were normal.

EFAST was negative for haemopericardium. Chest $\mathrm{x}$-ray showed the sharp object right into the left chest with minimal Pneumohaemothorax as shown in Figure 8 .
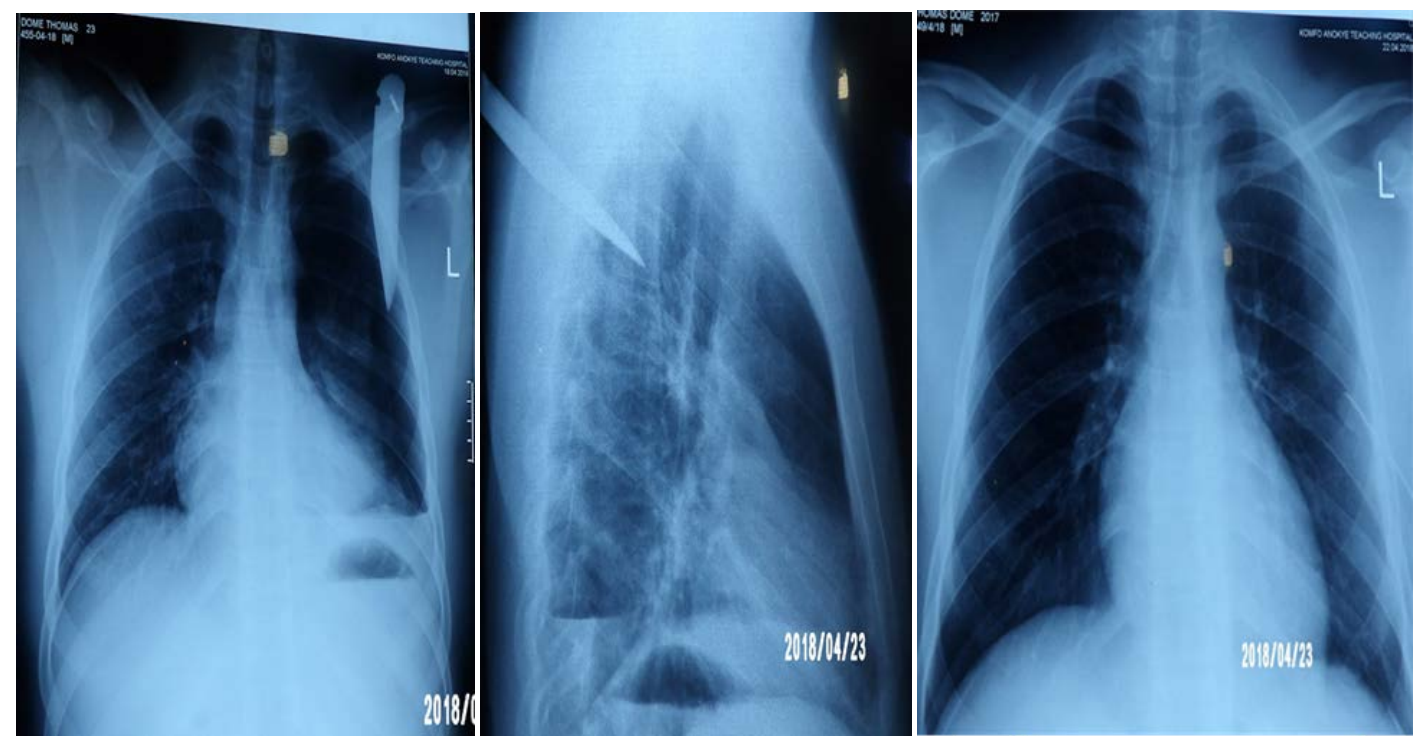

Figure 8. Chest $\mathrm{x}$-ray showing the knife in the chest and post-removal with chest tube in situ.

So a standard chest tube of size $32 \mathrm{Fr}$ was inserted draining bubbles of air and about $250 \mathrm{ml}$ of blood. The knife was then carefully removed under local lidocaine infiltration at the minor procedure room at the accident and the emergency centre of the hospital. He was monitored over 48 hours, monitoring the general haemodynamic status and the output from the chest tube. He did well and was discharged on day 4 after a repeat chest $x$-ray to confirm full lung expansion from the clinical examination, and the removal of the chest tube for a follow-up on outpatient basis. This patient did not have exploration through thoracotomy because his pleural complication was mainly pneumothorax with minimal haemothorax. One year after the incident, he has no complaints and going out his normal duties.

\subsection{Case 7}

Another young man of 42 years was also rushed to the accident and emergency centre with a knife at the back of the chest as shown in Figure 9. He was also allegedly attacked by colleagues following a misunderstanding. He was stable hemodynamically. It was safely removed and a chest tube passed draining bubbles of air and about $160 \mathrm{ml}$ of blood. He was also discharged on postoperative 5. Unfortunately, we lost him to follow-up. This patient did not have exploration via thoracotomy as was in case 6 , because the main pleural complication was pneumothorax with minimal haemothorax and therefore pleural drainage was adequate. 

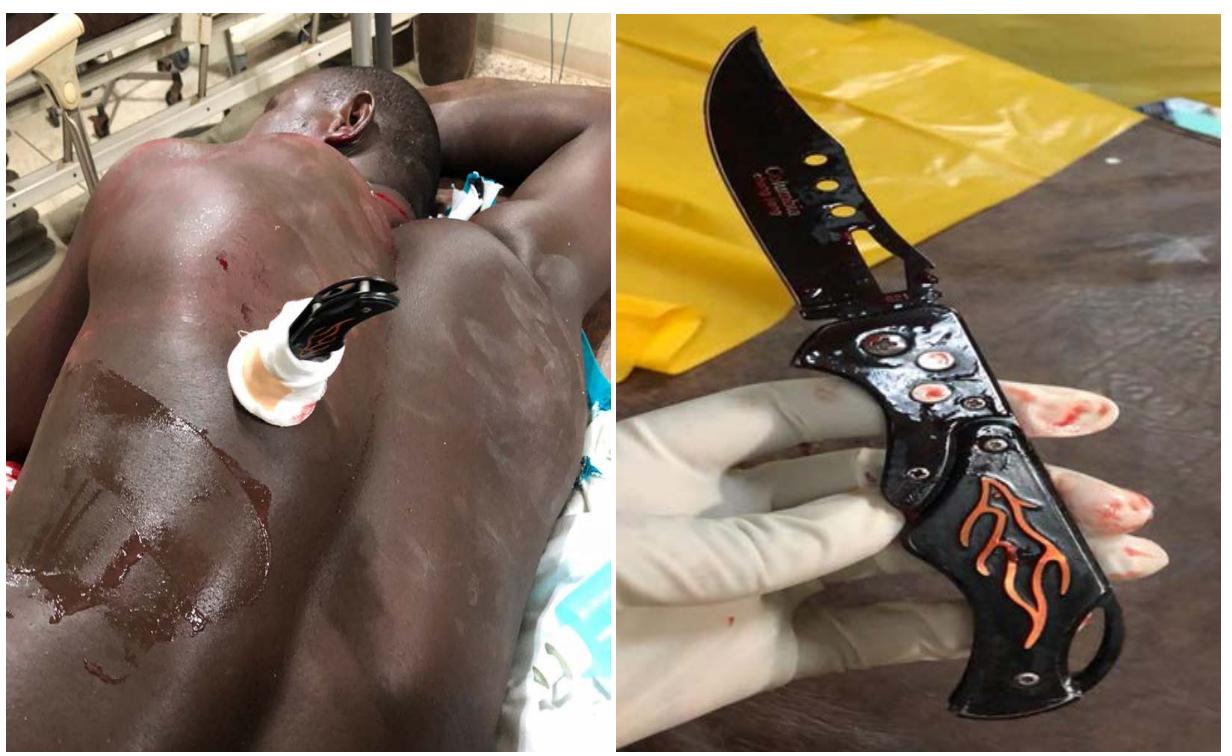

Figure 9. Showing the knife at the posterior chest wall and post removal.

\section{Discussion}

Impalement injuries consist of injuries in which large foreign objects pierce through a body cavity or any extremity and remain in place [1]. This definition fits consistently well with the cases presented herein. Thoracic impalement injuries are rare and dramatic occurrences especially in civilian populations with an associated high mortality particularly in the event of cardiac or major vascular involvements [2] [3]. We are presenting seven cases over a period of five years, however Edwin et al. in Accra, Ghana presented three cases over a period of same five years [3]. Cartwright and colleagues reported of mortality rates of about $40 \%$ in general population and almost $70 \%$ in those with cardiac involvement [4]. Young age and isolated pulmonary injuries have been found to account for favourable prognosis [2]. This observation correlates with our cases in which we had a young age group with the youngest being 12 years and the oldest being 42 years and therefore may have contributed to the zero mortality observed in our study. Impalement injuries commonly occur in road traffic accidents, airplane crashes and occupational injuries occurring at building sites according to Muhammad et al. [1]. However, we found physical attack with knife as the leading cause of the impalement injuries. Impalement injuries may be overtly visible or concealed in the thoracic cavity as was reported in a case series by Edwin et al. Overt thoracic impalement injuries have the foreign object protruding out thereby making its appreciation obvious and decision making not complicated. In concealed thoracic impalement injuries, the foreign body is completely lodged in the chest and draws no attention until severe complications develop [3]. Edwin et al. reported of an umbrella spoke which completely got lodged in the chest and subsequently resulted in development of recurrent haemoptysis from a pseudoaneurysm of the aortic isthmus. However all our cases were overt types making the presentation easier to appreciate and also motivat- 
ing the patients to be brought early to the hospital for management.

Thoracic impalement injuries, though rare, are most commonly observed on the right than the left because the presence of the heart and major vessels render survival in the event of their involvement exceptionally rare [5]. This is in direct contrast to our experience, since all our injuries occurred on the left side of the chest with one involving direct injury into the right ventricle, however all survived, probably from the early referrals and early intervention after stabilization. A case report by Pradhan and associates was one of the very few reported cases of impalement injury to the heart in which survival was reported. The right ventricle has been found to be the most commonly involved chamber followed by the left ventricle [6]. Similarly, our only case involving cardiac injury was into the right ventricle as well and she also survived.

Typically, the mechanism of injury of such injuries involve an impact between the body and the stationary foreign object which is typical of injuries occurring following road traffic accidents, attacks or falls from height. However, there have been reported cases where the impaling object is mobile [3]. Based on the mechanism of injury, impalement injuries have been divided into type I and type II injuries. Type I injuries, which are more common, involve the impaled object being stationary while Type II injuries involve a mobile foreign body being impaled into a body cavity [1] [5]. The type II is consistent with our cases, since five out of the seven cases were due to attacks with cases 2 and 5 being type I. Typically, clinical presentation and hemodynamic stability of a survivor of a thoracic impalement injury invariably depends on the extent of internal organ involvement. Due to the high mortality associated with thoracic impalement injuries, few patients are able to make it to the hospital in time for some life-saving interventions [5]. Patients should be seen as having sustained a major trauma for which the general protocols in management of thoracic trauma should be employed and this should begin even from the point of injury [3] [5]. Due to the uncertainty in the extent of injury sustained in thoracic impalement injuries, preoperative management is challenging. However, maintenance of airway, sustenance of breathing and optimization of circulation should remain paramount in the initial management [7]. The injured site should be carefully protected to avoid sudden removal of the impaled object [3] [5] [8]. There is a general consensus in multiple reported cases on the need to keep the impaled object in situ due to its tamponading effect since removal could lead to fatal exsanguination [1] [3] [5] [8]. The patient should be carefully assessed with extreme caution being taken to avoid mobilization of the object. There may be a need to significantly reduce the size of the impaled object [5]. Only one of the cases had the impaled object reduced in size and that was the case 5 , where the stick was cut to shorten it. Moreover, all the patients were brought to the hospital with some amount of protection of the foreign body with all kinds of material including gauze, cloth and normal saline bags.

Ideally, there should be no delay in conveying patient to the operating theatre 
while chasing radiological and laboratory investigations especially if patient is hemodynamically unstable because impalement injury is deemed a clinical diagnosis [3] [5] [6] [7] [8] [9]. However, in hemodynamically stable patients as were observed in our cases, the extent and severity of injury can be further evaluated by radiological interventions like chest radiography, computed tomography and aortic angiography [8]. Pradhan et al. in their case report utilized chest CT scan in their evaluation of a patient who surprisingly was hemodynamically stable despite coming in with an impalement injury to the heart [6]. However, we used chest radiography in most of our cases except the cardiac injury, the case 2, where we employed echocardiography to assist in localizing the position of the tip of the impaled crochet pin.

Due to the need for removal of the impaled object under direct vision, it is imperative that patients undergo surgical exploration so as to allow effective vascular and visceral repairs if needed [3] [8] [9] [10]. Surgical approaches for exploration in thoracic impalement injuries are generally limited to thoracotomy or sternotomy if mediastinal structures are implicated [3]. As a general rule of engagement, the incision made should span both entrance and exit wounds so as to gain adequate access for haemostasis [5]. In the event of major vascular injury, a cardiopulmonary bypass may be needed as was evident in a case report by Edwin and colleagues as well as Pradhan and associates [3] [6]. Decision on the type of thoracotomy incision should be made based on the trajectory of the impaled object [1]. After removal of the impaled object, thorough debridement is mandated along with copious irrigation followed postoperatively with broad-spectrum antibiotics to reduce the risk of infection [3] [5]. Depending on the extent of skin tissue loss, the defect may be closed primarily or reconstructed with flaps [5] [8]. We employed sternotomy in one case and thoracotomy in three cases. Two were managed with just wound exploration, impaled object removal and tube thoracostomy whereas the last one had just wound exploration and impaled object removal. Cases 6 and 7 were managed with chest tube insertion, removal of the impalement, and debridement and wound closure due to the minimal pleural complications from the injury which were mainly pneumothoraces with minimal haemothoraces and therefore pleural drainage was adequate. The case 4 with the stray round bullet on the aorta had no pleural complications and therefore the bullet was carefully removed under examination under anasethesia combined with wound exploration and repair.

Recently, there have been reports of thoracoscopic management of thoracic impalement injuries particularly in hemodynamically stable patients. It has been reported to have been utilized in the management of a case of a knife impaled in the chest by Burack et al. Use of Video Assisted Thoracic Surgery (VATS) procedure should be preceded by a thorough radiologic workup. It is recommended to tread with caution when employing VATS in managing major cardiovascular injuries. VATS has been found to be associated with reduced morbidity and hospital stay [10]. 


\section{Conclusion}

Thoracic impalement injuries are rare and among the most spectacular and dramatic traumatic injuries with high mortality. However, survival of a patient with thoracic impalement injury is possible even in less-resourced centers if the impaling object is not removed in the field coupled with the rapid transport of the patient to an appropriate hospital for stabilization and early emergency surgery.

\section{Acknowledgements}

Written informed consent was obtained from the patients for publication of these cases and accompanying images and we are grateful to the theatre staff at the Accident and Emergency centre of the Komfo Anokye Teaching Hospital.

\section{Conflicts of Interest}

The authors declare no conflicts of interest regarding the publication of this paper.

\section{References}

[1] Muhammad Afzal, R., Armughan, M., Javed, M.W., Rizvi, U.A. and Naseem, S. (2018) Thoracic Impalement Injury: A Survivor with Large Metallic Object in Situ. Chinese Journal of Traumatology, 21, 369-372. https://doi.org/10.1016/j.cjtee.2018.08.002

[2] Kiparakis, M., Lazopoulos, G., Gavalaki, A., Moniakis, A. and Chalkiadakis, G. (2015) Bilateral Thoracic Impalement through Mediastinum. The Annals of Thoracic Surgery, 99, 1452. https://doi.org/10.1016/j.athoracsur.2014.11.074

[3] Edwin, F., Tettey, M., Sereboe, L., Aniteye, E., Kotei, D., Tamatey, M., et al. (2009) Impalement Injuries of the Chest. Ghana Medical Journal, 43, 86-89. https://doi.org/10.4314/gmj.v43i2.55320 http://www.ncbi.nlm.nih.gov/pubmed/21326848

[4] Cartwright, A.J., Taams, K.O., Unsworth-White, M.J., Mahmood, N. and Murphy, P.M. (2001) Suicidal Nonfatal Impalement Injury of the Thorax. The Annals of Thoracic Surgery, 72, 1364-1366. https://doi.org/10.1016/S0003-4975(00)02471-1

[5] Lunca, S., Morosanu, C., Alexa, O. and Pertea, M. (2015) Severe Thoracic Impalement Injury: Survival in a Case with Delayed Surgical Definitive Care. Turkish Journal of Trauma \& Emergency Surgery, 21, 152-156. https://doi.org/10.5505/tjtes.2015.38354

[6] Pradhan, S., Sapkota, R., Shrestha, U.K., Amatya, R. and Koirala, B. (2011) Impalement Injury to the Heart. Kathmandu University Medical Journal, 9, 80-82. https://doi.org/10.3126/kumj.v9i1.6270

[7] Sawhney, C., D’souza, N., Mishra, B., Gupta, B. and Das, S. (2009) Management of a Massive Thoracoabdominal Impalement: A Case Report. Scandinavian Journal of Trauma, Resuscitation and Emergency Medicine, 17, 50. https://doi.org/10.1186/1757-7241-17-50

[8] Bowley, D.M., Gordon, M.P. and Boffard, K.D. (2003) Thoracic Impalement after Ultralight Aircraft Crash. The Journal of Thoracic and Cardiovascular Surgery, 125, 954-955. https://doi.org/10.1067/mtc.2003.200

[9] Shitaka, H., Tsuchishima, S., Sakamoto, S., Nagayoshi, Y., Shono, S., Nishizawa, H., 
et al. (2001) Recovery of an Impalement and Transfixion Chest Injury by a Reinforced Steel Bar. Annals of Thoracic and Cardiovascular Surgery, 7, 304-306.

[10] Burack, J.H., Amulraj, E.A., O’Neill, P., Brevetti, G. and Lowery, R.C. (2005) Thoracoscopic Removal of a Knife Impaled in the Chest. The Journal of Thoracic and Cardiovascular Surgery, 130, 1213-1214. https://doi.org/10.1016/j.jtcvs.2005.05.050 